\title{
Prognostic Significance of Time to Castration Resistance in Patients With Metastatic Castration-sensitive Prostate Cancer
}

\author{
HIDEAKI MIYAKE, YUTO MATSUSHITA, HIROMITSU WATANABE, KEITA TAMURA, \\ DAISUKE MOTOYAMA, TOSHIKI ITO, TAKAYUKI SUGIYAMA and ATSUSHI OTSUKA \\ Department of Urology, Hamamatsu University School of Medicine, Hamamatsu, Japan
}

\begin{abstract}
Background/Aim: It is important to delay the emergence of castration-resistant phenotype to improve the prognosis in patients with metastatic castration-sensitive prostate cancer ( $m C S P C)$. The objective of this study was to investigate the prognostic impact of time to castration resistance (TTCR) in $m$ CSPC patients. Patients and Methods: This study included 437 consecutive mCSPC patients whose primary androgen deprivation therapy was judged to have failed. Prognostic outcomes in these patients were investigated by dividing them into the following 4 groups of 82, 104, 133 and 118 patients with TTCR 0-6, 6.1-12, 12.1-18 and $\geq 18.1$ months, respectively. Results: The mean value of TTCR in the 437 patients was 18.7 months. Of several baseline parameters, significant differences among the 4 groups were noted in the performance status, prostate-specific antigen (PSA) level, lactate dehydrogenase ( $L D H)$ level, alkaline phosphatase $(A L P)$ level and Gleason score, all of which favored longer TTCR groups. Furthermore, despite the lack of a significant difference in time from the development of castration-resistant disease to death among the 4 groups, there was a significant difference in overall survival (OS) from diagnosis among these groups, showing prolonged OS proportional to TTCR. Univariate analysis identified the age, PSA level, LDH level, ALP level, Gleason score, visceral metastasis and TTCR as significant predictors of $O S$, of which only age, ALP level and TTCR were shown to be independently associated with OS on multivariate analysis. Conclusion: $\mathrm{mCSPC}$ patients with a longer TTCR are likely to achieve a more favorable OS.
\end{abstract}

Prostate cancer (PC) represents the most commonly diagnosed malignancy and is the second leading cause of

Correspondence to: Hideaki Miyake, Department of Urology, Hamamatsu University School of Medicine, 1-20-1 Handayama, Higashi-Ku, Hamamatsu 431-3192, Japan. Tel: +81 534352306, Fax: +81 534352305, e-mail: hideakimiyake@ hotmail.com

Key Words: Time to castration resistance, metastatic castrationsensitive prostate cancer, overall survival. cancer-related mortality in men in Western industrialized countries (1). The prognostic outcomes in patients with advanced PC have been improved due to recent advances characterized by the introduction of several novel agents for patients with castration-resistant PC (CRPC), including abiraterone acetate, enzalutamide, and cabazitaxel (2-4). Among patients with advanced PC, however, there remains a proportion with poor prognostic outcomes, such as those newly diagnosed with de novo metastatic diseases $(5,6)$. Accordingly, it is necessary to conduct a detailed survey focusing on such a patient cohort in order to further improve the survival of patients with advanced PC.

Recently, combined treatment with primary androgen deprivation therapy (ADT) and a novel additional agent was demonstrated to significantly improve the prognosis of patients with newly diagnosed metastatic castration-sensitive PC (mCSPC), particularly those with a high-risk disease (7-10). For example, Sweeney et al. conducted the CHAARTED trial comparing the efficacy of ADT alone and ADT plus docetaxel in patients with $\mathrm{mCSPC}$, and showed the significantly longer overall survival (OS) of the combination arm compared to ADT alone (7), while Fizazi et al. reported that the addition of abiraterone acetate and prednisone to ADT significantly improved OS in patients with high-risk mCSPC compared to ADT plus placebo in the LATITUDE trial (9). These outcomes suggest that it is important to delay the emergence of CRPC by providing a powerful treatment for newly-diagnosed mCSPC patients to achieve favorable prognostic outcomes; however, limited information remains available with respect to the impact of time to castration resistance (TTCR) in patients with mCSPC.

Considering these findings, we retrospectively obtained data from a total of 437 patients with mCSPC who were treated with primary ADT, then diagnosed with the development of CRPC, and investigated the prognostic outcomes according to TTCR in these patients.

\section{Patients and Methods}

Patients. This was conducted as a retrospective study by reviewing clinicopathological data from consecutive Japanese patients newly diagnosed with mCSPC who received primary ADT between 
Table I. Baseline characteristics of metastatic castration-sensitive prostate cancer patients according to time to castration resistance

\begin{tabular}{|c|c|c|c|c|c|}
\hline \multirow[b]{2}{*}{ Variables $(\%)$} & \multicolumn{5}{|c|}{ Time to castration resistance (months) } \\
\hline & $\begin{array}{c}0-6 \\
(\mathrm{n}=82)\end{array}$ & $\begin{array}{c}6.1-12 \\
(\mathrm{n}=104)\end{array}$ & $\begin{array}{l}12.1-18 \\
(\mathrm{n}=133)\end{array}$ & $\begin{array}{c}\geq 18.1 \\
(\mathrm{n}=118)\end{array}$ & $p$-Value \\
\hline Age (years) & & & & & 0.71 \\
\hline$\leq 70$ & $44(53.7)$ & $53(51.0)$ & $65(48.9)$ & $52(44.1)$ & \\
\hline$>70$ & $38(46.3)$ & $51(49.0)$ & $68(51.1)$ & $66(55.9)$ & \\
\hline Performance status & & & & & $<0.001$ \\
\hline 0 or 1 & $57(69.5)$ & $80(76.9)$ & $119(82.7)$ & $104(88.1)$ & \\
\hline$\geq 2$ & $25(30.5)$ & $24(23.1)$ & $14(17.3)$ & $14(11.9)$ & \\
\hline PSA (ng/ml) & & & & & 0.04 \\
\hline$\leq 100$ & $33(40.2)$ & $47(45.2)$ & $72(54.1)$ & $69(58.5)$ & \\
\hline$>100$ & $49(59.8)$ & $57(54.8)$ & $61(45.9)$ & $49(41.5)$ & \\
\hline $\mathrm{Hb}(\mathrm{g} / \mathrm{dl})$ & & & & & 0.83 \\
\hline$\leq 12$ & $44(53.7)$ & $54(51.9)$ & $66(49.6)$ & $56(47.5)$ & \\
\hline$>12$ & $38(46.3)$ & $50(48.1)$ & $67(50.4)$ & $62(52.5)$ & \\
\hline $\mathrm{Alb}(\mathrm{mg} / \mathrm{dl})$ & & & & & 0.94 \\
\hline$\leq 3.5$ & $43(52.4)$ & $52(50.0)$ & $65(48.9)$ & $57(48.3)$ & \\
\hline$>3.5$ & $39(47.6)$ & $52(50.0)$ & $68(51.1)$ & $61(51.7)$ & \\
\hline LDH (IU/1) & & & & & 0.026 \\
\hline$\leq 300$ & $33(40.2)$ & $44(42.3)$ & $70(52.6)$ & $69(58.5)$ & \\
\hline$>300$ & $49(59.8)$ & $60(57.7)$ & $63(47.4)$ & $49(41.5)$ & \\
\hline ALP (IU/l) & & & & & 0.0061 \\
\hline$\leq 400$ & $30(36.6)$ & $42(40.4)$ & $68(51.1)$ & $69(58.5)$ & \\
\hline$>400$ & $52(63.4)$ & $62(59.6)$ & 65 (48.9) & $49(41.5)$ & \\
\hline Gleason score & & & & & 0.0011 \\
\hline$\leq 8$ & $7(8.5)$ & $21(20.2)$ & $38(28.6)$ & $36(30.5)$ & \\
\hline 9 or 10 & $75(91.5)$ & $83(79.8)$ & $95(71.4)$ & $82(69.5)$ & \\
\hline Bone metastasis & & & & & 0.13 \\
\hline No & $2(2.4)$ & $2(2.4)$ & $0(0)$ & $0(0)$ & \\
\hline Yes & $80(97.6)$ & $102(98.1)$ & $133(100)$ & $118(100)$ & \\
\hline Lymph node metastasis & & & & 0.72 & \\
\hline No & $41(50.0)$ & $54(51.9)$ & $70(52.6)$ & $68(57.6)$ & \\
\hline Yes & $41(50.0)$ & $50(48.1)$ & $63(47.4)$ & $50(42.4)$ & \\
\hline Visceral metastasis & & & & & 0.0075 \\
\hline No & $76(92.7)$ & $99(95.2)$ & $131(98.5)$ & $116(98.3)$ & \\
\hline Yes & $6(7.3)$ & $5(4.8)$ & $2(1.5)$ & $2(1.7)$ & \\
\hline
\end{tabular}

PSA, Prostate-specific antigen; Hb, hemoglobin; Alb, albumin; LDH, lactate dehydrogenase; ALP, alkaline phosphatase.

January 2010 and December 2017, and were subsequently diagnosed with the development of CRPC in a routine clinical setting at our institution. After excluding patients without full data scheduled to be analyzed and those who died prior to diagnosis with CRPC, a total of $437 \mathrm{mCSPC}$ patients were included in this study. The Research Ethics Committee of Hamamatsu University School of Medicine approved the design of this study, and the need to obtain informed consent for involvement in it from all of the included patients was waived because of its retrospective design.

Treatment. All the patients included in this study were judged to have prostatic adenocarcinoma by histopathological examination, and were initially treated with primary ADT, either by castration therapy or combined androgen blockade consisting of castration plus bicalutamide. According to either the Prostate Cancer Working Group 2 (PCWG2) criteria (11) or the Response Evaluation Criteria in Solid Tumors (12), disease progression against primary ADT, indicating the emergence of CRPC, was defined as prostate-specific antigen (PSA) or radiographic progression, respectively, in patients maintaining a serum testosterone level $<50 \mathrm{ng} / \mathrm{dl}$. After the failure of primary ADT, a wide variety of patterns of sequential therapy using several agents, such as flutamide, abiraterone acetate, enzalutamide, docetaxel and cabazitaxel, were subsequently provided according to the preference of the physicians as well as patients, without strictly regulated criteria. In this series, TTCR was defined as the duration from the introduction to failure of primary ADT, and the patients were classified into 4 subgroups according to TTCR as follows: $0-6,6.1-12,12.1-18$, and $\geq 18.1$ months.

Evaluation. The clinicopathological data were obtained from the medical records of each patient. Before starting primary ADT, the Eastern Cooperative Oncology Group (ECOG) performance status (PS) was evaluated, and the status of metastatic spread was examined using computed tomography and radionuclide bone scans. All laboratory data, including hemoglobin $(\mathrm{Hb})$, albumin (Alb), lactate 


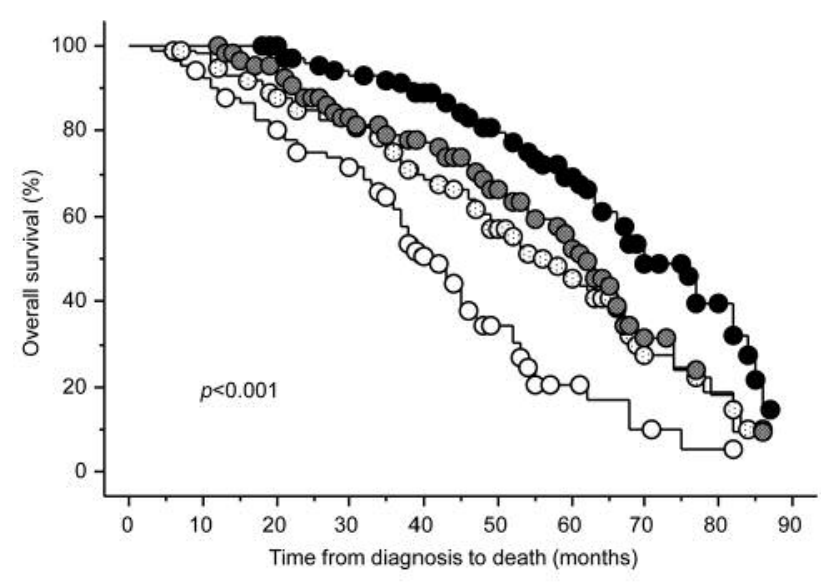

\begin{tabular}{|ll|}
\hline \multicolumn{1}{|c|}{ TTCR (months) } \\
0 & $0-6$ \\
0 & $6.1-12$ \\
0 & $12.1-18$ \\
0 & $\geq 18.1$ \\
\hline
\end{tabular}

Figure 1. Overall survival from diagnosis in patients with metastatic castration-sensitive prostate cancer who received primary androgen deprivation therapy and subsequently developed castration-resistant prostate cancer according to the time to castration resistance (TTCR).
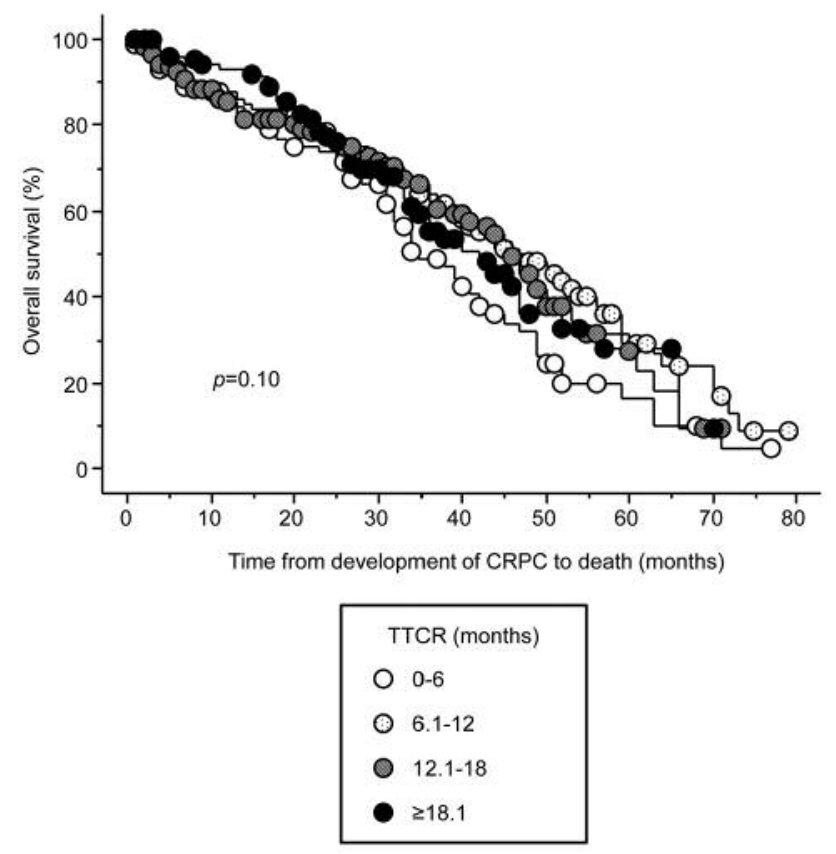

Figure 2. Overall survival from the development of castration-resistant prostate cancer (CRPC) in patients with metastatic castration-sensitive prostate cancer who received primary androgen deprivation therapy according to the time to castration resistance (TTCR).

Prognosis according to TTCR. After the diagnosis of CRPC, 225 patients died, consisting of 59 (72.0\%), 62 (59.6\%), 61 $(43.6 \%)$ and $51(39.0 \%)$ with TTCR from $0-6,6.1-12,12.1$ 18 , and $\geq 18.1$ months, respectively. The OS from diagnosis was 40.8, 57.1, 62.2 and 70.1 months in patients with TTCR $0-6,6.1-12,12.1-18$, and $\geq 18.1$ months, respectively. As shown in Figure 1, there was a significant difference in OS from diagnosis among the 4 groups.

The median time from the development of CRPC to death was 35.2, 47.8, 46.3 and 42.3 months in patients with TTCR $0-6,6.1-12,12.1-18$, and $\geq 18.1$ months, respectively. No significant difference in OS from the development of CRPC was noted among the 4 groups (Figure 2).

Prognostic impact of TTCR. In order to further clarify the prognostic significance of TTCR, the association between OS from diagnosis and several clinicopathological parameters was assessed by univariate and multivariate analyses. As shown in Table II, the age, PSA level, LDH level, ALP level, Gleason score, visceral metastasis and TTCR were identified as significant predictors of OS on univariate analysis. Of these significant factors, only the age, ALP level and TTCR were shown to be independently associated with OS on multivariate analysis. 
Table II. Uni- and multivariate analyses of impacts of various parameters on overall survival from diagnosis in patients with metastatic castrationsensitive prostate cancer.

\begin{tabular}{|c|c|c|c|c|}
\hline \multirow[b]{2}{*}{ Variables } & \multicolumn{2}{|c|}{ Univariate analysis } & \multicolumn{2}{|c|}{ Multivariate analysis } \\
\hline & HR $(95 \% \mathrm{CI})$ & $p$-Value & $\operatorname{HR}(95 \% \mathrm{CI})$ & $p$-Value \\
\hline Age (years) $(\leq 70$ versus $>70)$ & $0.28(0.21-0.47)$ & 0.037 & $0.33(0.25-0.57)$ & 0.039 \\
\hline Performance status ( 0 or 1 versus $\geq 2$ ) & $0.59(0.45-1.07)$ & 0.11 & - & - \\
\hline PSA $(\mathrm{ng} / \mathrm{mL})(\leq 100$ versus $>100)$ & $0.38(0.29-0.56)$ & 0.044 & $0.47(0.40-1.37)$ & 0.27 \\
\hline $\mathrm{Hb}(\mathrm{g} / \mathrm{dL})(\leq 12$ versus $>12)$ & $1.24(0.83-1.68)$ & 0.36 & - & - \\
\hline Alb $(\mathrm{mg} / \mathrm{dL})(\leq 3.5$ versus $>3.5)$ & $1.20(0.91-1.58)$ & 0.37 & - & - \\
\hline LDH $(\mathrm{IU} / \mathrm{L})(\leq 300$ versus $>300)$ & $0.32(0.18-0.46)$ & 0.039 & $0.43(0.39-1.18)$ & 0.18 \\
\hline ALP (IU/L) $(\leq 400$ versus $>400)$ & $0.29(0.19-0.51)$ & 0.035 & $0.35(0.21-0.55)$ & 0.036 \\
\hline Gleason score $(\leq 8$ versus $\geq 9$ or 10$)$ & $0.39(0.22-0.58)$ & 0.041 & $0.52(0.38-1.89)$ & 0.43 \\
\hline Bone metastasis (no versus yes) & $1.17(0.73-2.55)$ & 0.43 & - & - \\
\hline Lymph node metastasis (no versus yes) & $0.89(0.68-1.70)$ & 0.39 & - & - \\
\hline Visceral metastasis (no versus yes) & $0.36(0.29-0.60)$ & 0.032 & $0.55(0.27-1.79)$ & 0.4 \\
\hline Time to castration resistance (months) ( $\leq 12$ versus $>12$ ) & $3.46(1.72-5.58)$ & 0.023 & $3.23(1.89-4.68)$ & 0.027 \\
\hline
\end{tabular}

HR, Hazard ratio; CI, confidence interval; PSA, prostate-specific antigen; Hb, hemoglobin; Alb, albumin; LDH, lactate dehydrogenase; ALP, alkaline phosphatase.

\section{Discussion}

In recent years, marked changes in the therapeutic strategy for patients with advanced PC have taken place due to the introduction of several novel agents into real-world clinical practice, resulting in the significant improvement of survival in these patients (2-4), whereas PC accounts for approximately $10 \%$ of overall estimated cancer deaths and remains the second most common cause of cancer-related mortality in Western industrialized countries (1). To date, there have been a number of studies characterizing prognostic features in advanced PC patients, which identified the presence of metastases at diagnosis as one of the most critical factors associated with PC-specific death $(5,6,13-17)$. More recently, however, the addition of treatment with either docetaxel or abiraterone acetate to primary ADT has been shown to significantly prolong OS of patients with mCSPC (7-10). Collectively, these findings suggest that it might be important to increase TTCR from the initiation of primary ADT in order to improve the prognosis of PC patients, particularly those with unfavorable characteristics, like de novo metastases; therefore, in this study, we retrospectively analyzed the data from a total of $437 \mathrm{mCSPC}$ patients who received primary ADT and subsequently developed mCRPC focusing on the impact of TTCR on their prognostic outcomes.

In this series, the mean TTCR of the study cohort was 18.7 months, which is similar to those in recent studies (5, 13-15). For example, Zacho et al. reported that the median time of TTCR in 149 CRPC patients treated with ADT was 20 months (13). We then compared the clinicopathological characteristics of the $437 \mathrm{mCSPC}$ patients by dividing them into 4 groups according to TTCR, and found that patients with a shorter TTCR were likely to have factors associated with unfavorable oncological outcomes, including a poor PS, high PSA level, high LDH level, high ALP level and high Gleason score. Based on this outcome, PC showing rapid progression following the introduction of primary ADT may be regarded as having an aggressive phenotype.

It is of interest to assess the clinical course of mCSPC patients according to TTCR. In this series, OS from diagnosis in mCSPC patients was shown to have a significant correlation with TTCR. To our knowledge, this is the first report showing prolonged OS from diagnosis in mCSPC patients proportional to TTCR. However, time from CRPC to death in MCSPC patients was not affected by TTCR, suggesting that once CRPC has developed, a similar clinical course may be expected in PC patients, irrespective of prior clinical profiles, including TTCR. In fact, Frees $e t$ al. retrospectively analyzed OS in PC patients according to the time to metastasis, and showed that despite the significant effect of time to metastasis on OS, there was no difference in time from CRPC to death among groups stratified based on time to metastasis (5). Considering these findings, it is extremely important to prolong TTCR as long as possible in order to achieve favorable prognostic outcomes in mCSPC patients.

Another point of interest is the prognostic impact of TTCR on OS of mCSPC patients. To date, there have been various factors identified as predictors of OS in newly diagnosed PC, such as the PSA level, nadir PSA level after ADT, metastatic status, Gleason score and ALP level (5, 6, 13-15). In this series, TTCR in addition to the age and ALP level were shown to be independently associated with OS on multivariate analysis. Similarly, TTCR was suggested to have an independent effect on OS of PC patients in a previous study reported by Frees et al. (5). These findings 
also support the significance of prolonged TTCT in the improvement of OS from diagnosis in mCSPC patients which could be dominantly affected by TTCT rather than time from CRPC to death. Accordingly, a favorable OS might be expected by the simultaneous introduction of primary ADT plus either docetaxel or abiraterone acetate, which were demonstrated to markedly prolong TTCR in newly diagnosed PC patients, particularly in those with unfavorable characteristics $(8,9)$.

We would like to describe several limitations of this study. Firstly, although a comparatively large number of patients were included, this was a retrospective study performed without strict criteria; that is, existence of varied options in terms of the type of primary ADT, selection of agents after the failure of ADT, dosing schedule of each agent and follow-up schedule. Secondly, due to the long duration of this study, patients with heterogeneous therapeutic backgrounds were simultaneously included. In particular, introduction of novel agents targeted against CRPC patients, such as abiraterone acetate, enzalutamide and cabazitaxel, during the study period may have affected the outcomes (2-4). Considering the significant improvement of OS by these novel agents, the impact of TTCR on OS from diagnosis may be relatively weakened in patients being treated with these agents. Thirdly, when interpreting the outcomes of the present study, it should be taken into consideration that marked changes in primary ADT will definitely occur with the combined use of either abiraterone acetate or docetaxel (7-10).

\section{Conclusion}

mCSPC patients with a shorter TTCR were significantly more likely to exhibit unfavorable clinicopathological characteristics, and OS from diagnosis. However, time from CRPC to death, was not significantly affected by TTCR in the study cohort. Moreover, TTCR was identified as one of the independent predictors of OS from diagnosis on multivariate analysis of several parameters. Collectively, these findings strongly suggest that prolonging TTCR in mCSPC patients could be the key factor in order to achieve longer OS.

\section{Conflicts of Interest}

The authors have no conflict of interest to declare.

\section{Authors' Contributions}

The types of contribution by each author are as follows: Study conception and design, Hideaki Miyake; Acquisition of data, Yuto Matsushita, Hiromitsu Watanabe, Keita Tamura, Daisuke Motoyama, Toshiki Ito, Takayuki Sugiyama; Analysis and interpretation of data, Hideaki Miyake, Atsushi Otsuka; Drafting of manuscript and critical revision, Hideaki Miyake.

\section{Acknowledgements}

No funding or sponsorship was received for this study or publication of this article.

\section{References}

1 Torre LA, Bray F, Siegel RL, Ferlay J, Lortet-Tieulent J and Jemal A: Global cancer statistics, 2012. CA Cancer J Clin 65: 87-108, 2015. PMID: 25651787, doi: 10.3322/caac.21262

2 Fitzpatrick JM, Bellmunt J, Fizazi K, Fizazi K, Heidenreich A, Sternberg CN, Tombal B, Alcaraz A, Bahl A, Bracarda S, Di Lorenzo G, Efstathiou E, Finn SP, Fosså S, Gillessen S, Kellokumpu-Lehtinen PL, Lecouvet FE, Oudard S, de Reijke TM, Robson CN, De Santis M, Seruga B and de Wit R: Optimal management of metastatic castration-resistant prostate cancer: highlights from a European Expert Consensus Panel. Eur J Cancer 50: 1617-1627, 2014. PMID: 24703899, doi: 10.1016/j.ejca.2014.03.010

3 Chi K, Hotte SJ, Joshua AM, North S, Wyatt AW, Collins LL and Saad F: Treatment of mCRPC in the AR-axis-targeted therapy-resistant state. Ann Oncol 26: 2044-2056, 2015. PMID: 26101426, doi: 10.1093/annonc/mdv267

4 Ceder Y, Bjartell A, Culig Z, Rubin MA, Tomlins S and Visakorpi T: The molecular evolution of castration-resistant prostate cancer. Eur Urol Focus 2: 506-513, 2016. PMID: 28723516, doi: 10.1016/j.euf.2016.11.012

5 Frees S, Akamatsu S, Bidnur S, Khalaf D, Chavez-Munoz C, Struss W, Eigl BJ, Gleave M, Chi KN and So A: The impact of time to metastasis on overall survival in patients with prostate cancer. World J Urol 36: 1039-1046, 2018. PMID: 29488095, doi: 10.1007/s00345-018-2236-4

6 Patrikidou A, Loriot Y, Eymard JC, Albiges L, Massard C, Ileana E, Di Palma M, Escudier B and Fizazi K: Who dies from prostate cancer? Prostate Cancer Prostatic Dis 17: 348-352, 2014. PMID: 25311767, doi: 10.1038/pcan.2014.35

7 Sweeney CJ, Chen YH, Carducci M, Liu G, Jarrard DF, Eisenberger M, Wong YN, Hahn N, Kohli M, Cooney MM, Dreicer R, Vogelzang NJ, Picus J, Shevrin D, Hussain M, Garcia JA and DiPaola RS: Chemohormonal therapy in metastatic hormone-sensitive prostate cancer. N Engl J Med 373: 737-746, 2015. PMID: 26244877, doi: 10.1056/NEJMoa1503747

8 James ND, Sydes MR, Clarke NW, Mason MD, Dearnaley DP, Spears MR, Ritchie AW, Parker CC, Russell JM, Attard G, de Bono J, Cross W, Jones RJ, Thalmann G, Amos C, Matheson D, Millman R, Alzouebi M, Beesley S, Birtle AJ, Brock S, Cathomas R, Chakraborti P, Chowdhury S, Cook A, Elliott T, Gale J, Gibbs S, Graham JD, Hetherington J, Hughes R, Laing R, McKinna F, McLaren DB, O'Sullivan JM, Parikh O, Peedell C, Protheroe A, Robinson AJ, Srihari N, Srinivasan R, Staffurth J, Sundar S, Tolan S, Tsang D, Wagstaff J and Parmar MK: Addition of docetaxel, zoledronic acid, or both to first-line longterm hormone therapy in prostate cancer (STAMPEDE): survival results from an adaptive, multiarm, multistage, platform randomised controlled trial. Lancet 387: 1163-1177, 2016. PMID: 26719232, doi: 10.1016/S0140-6736(15)01037-5

9 Fizazi K, Tran N, Fein L, Matsubara N, Rodriguez-Antolin A, Alekseev BY, Özgüroğlu M, Ye D, Feyerabend S, Protheroe A, De Porre P, Kheoh T, Park YC, Todd MB and Chi KN: Abiraterone plus prednisone in metastatic, castration-sensitive 
prostate cancer. N Engl J Med 377: 352-360, 2017. PMID 28578607, doi: 10.1056/NEJMoa1704174

10 Crawford ED, Shore ND, Petrylak DP, Higano CS and Ryan CJ: Abiraterone acetate and prednisone in chemotherapy-naïve prostate cancer patients: rationale, evidence and clinical utility. Ther Adv Med Oncol 9: 319-333, 2017. PMID: 28529549, doi: $10.1177 / 1758834017698644$

11 Scher HI, Halabi S, Tannock I, Morris M, Sternberg CN, Carducci MA, Eisenberger MA, Higano C, Bubley GJ, Dreicer R, Petrylak D, Kantoff P, Basch E, Kelly WK, Figg WD, Small EJ, Beer TM, Wilding G, Martin A and Hussain M: Design and end points of clinical trials for patients with progressive prostate cancer and castrate levels of testosterone: recommendations of the Prostate Cancer Clinical Trials Working Group. J Clin Oncol 26: 11481159, 2008. PMID: 18309951, doi: 10.1200/ JCO.2007.12.4487

12 Eisenhauer EA, Therasse P, Bogaerts J, Schwartz LH, Sargent D, Ford R, Dancey J, Arbuck S, Gwyther S, Mooney M, Rubinstein L, Shankar L, Dodd L, Kaplan R, Lacombe D and Verweij J: New response evaluation criteria in solid tumours: revised RECIST guideline (version 1.1). Eur J Cancer 45: 228247, 2009. PMID: 19097774, doi: 10.1016/j.ejca.2008.10.026

13 Zacho HD, Gade M, Mortensen JC, Bertelsen H, Boldsen SK, Barsi $\mathrm{T}$ and Petersen LJ: Bone scan index is an independent predictor of time to castration-resistant prostate cancer in newly diagnosed prostate cancer: a prospective study. Urology 108: 135141, 2017. PMID: 28760556, doi: 10.1016/ j.urology.2017.05.058
14 Sim HG, Lau WK and Cheng CW: Predictors of androgen independence in metastatic prostate cancer. BJU Int 93: 12211224, 2004. PMID: 15180610

15 Smaletz O, Scher HI, Small EJ, Verbel DA, McMillan A, Regan K, Kelly WK and Kattan MW: Nomogram for overall survival of patients with progressive metastatic prostate cancer after castration. J Clin Oncol 20: 3972-3982, 2002. PMID: 12351594

16 Bournakis E, Efstathiou E, Varkaris A, Wen S, Chrisofos M, Deliveliotis C, Alamanis C, Anastasiou I, Constantinides C, Bamias A and Dimopoulos MA: Time to castration resistance is an independent predictor of castration-resistant prostate cancer survival. Anticancer Res 31: 1475-1482, 2011. PMID: 21508406

17 Hung SC, Wang SS, Li JR, Chen MC, Yang CK, Chen CS, Ho HC, Chiu KY, Cheng CL, Chang CH and Ou YC: Outcome of patients with metastatic castration-resistant prostate cancer after PSA progression with abiraterone acetate. Anticancer Res 38: 54295436, 2018. PMID: 30194199, doi: 10.21873/anticanres.12874

Received January 10, 2019

Revised January 24, 2019

Accepted January 28, 2019 